\title{
Diagnostic validity of fatal cerebral strokes and coronary deaths in mortality statistics: an autopsy study
}

\author{
Anne K. Gulsvik • Amund Gulsvik • \\ Einar Svendsen • Bjørn O. Mæhle • \\ Dag S. Thelle • Torgeir B. Wyller
}

Received: 13 April 2010/Accepted: 3 December 2010/Published online: 18 December 2010

(C) The Author(s) 2010. This article is published with open access at Springerlink.com

\begin{abstract}
Mortality statistics represent important endpoints in epidemiological studies. The diagnostic validity of cerebral stroke and ischemic heart disease recorded as the underlying cause of death in Norwegian mortality statistics was assessed by using mortality data of participants in the Bergen Clinical Blood Pressure Study in Norway and autopsy records from the Gade Institute in Bergen. In the 41 years of the study (1965-2005) 4,387 subjects had died and 1,140 (26\%) had undergone a post mortem examination; 548 (12\%) died from cerebral stroke and $1,120(24 \%)$ from ischemic heart disease according to the mortality statistics, compared to $113(10 \%)$ strokes and $323(28 \%)$ coronary events registered in the autopsy records. The sensitivity and positive predictive value of
\end{abstract}

A. K. Gulsvik - T. B. Wyller

Department of Geriatric Medicine, Institute of Clinical

Medicine, Oslo University Hospital, University of Oslo, Oslo,

Norway

A. K. Gulsvik ( $\square)$

Department of Geriatric Medicine, Ullevaal University Hospital, 0407 Oslo, Norway

e-mail: a.k.gulsvik@medisin.uio.no

A. Gulsvik

Department of Thoracic Medicine, Institute of Medicine,

University of Bergen, Bergen, Norway

E. Svendsen · B. O. Mæhle

Department of Pathology, The Gade Institute,

Haukeland University Hospital, University of Bergen,

Bergen, Norway

D. S. Thelle

Department of Biostatistics, Institute of Basic Medical Sciences, University of Oslo, Oslo, Norway fatal cerebral strokes in the mortality statistics were 0.75 , 95\% confidence interval (CI) $[0.66,0.83]$ and $0.86[0.77$, $0.92]$, respectively, whereas those of coronary deaths were $0.87[0.84,0.91]$ and 0.85 [0.81, 0.89] respectively. Cohen's Kappa coefficients were 0.78 [0.72, 0.84] for stroke and $0.80[0.76,0.84]$ for coronary deaths. In addition to female gender and increasing age at death, cerebral stroke was a negative predictor of an autopsy being carried out (odds ratio (OR) $0.69,95 \%$ CI [0.54, $0.87]$ ), whereas death from coronary heart disease was not (OR 1.14, 95\% CI [0.97, 1,33]), both adjusted for gender and age at death. There was substantial agreement between mortality statistics and autopsy findings for both fatal strokes and coronary deaths. Selection for post mortem examinations was associated with age, gender and cause of death.

Keywords Autopsy $\cdot$ Stroke $\cdot$ Ischemic heart disease · Death certification · Validity $\cdot$ Mortality statistics

\begin{tabular}{|c|c|}
\hline \multicolumn{2}{|c|}{ Abbreviations } \\
\hline ICD & International Classification of Diseases \\
\hline PPV & Positive predictive value \\
\hline $\mathrm{CI}$ & Confidence interval \\
\hline $\mathrm{N}$ & Number of cases \\
\hline OR & Odds ratio \\
\hline SPSS & Statistical Package of Social Science \\
\hline SNOMED & $\begin{array}{l}\text { Systematic Nomenclature of Medicine } \\
\text { (pathology-coding system) }\end{array}$ \\
\hline $\mathrm{T}$ code & Topographical code \\
\hline M code & Morphological code \\
\hline Eurocodes & $\begin{array}{l}65 \text { Different groups of ICD-codes on causes } \\
\text { of death which are used in the European } \\
\text { official mortality statistics }\end{array}$ \\
\hline
\end{tabular}




\section{Introduction}

The specific cause of death reported in mortality statistics is a common endpoint in epidemiological studies and it is generally used as a surrogate marker of morbidity. Ischemic heart disease and cerebral stroke are the two leading causes of death in the industrialized parts of world according to mortality statistics [ 1 265/id]. Both the disability and mortality attributable to vascular disease in ageing populations highlight the need to identify factors related to aetiology and prevention.

Despite the decreasing autopsy rates, post mortem examination is still regarded as the most accurate means of determining the cause of death [2 299/id, 3 285/id].

Previous studies on the validity of cerebrovascular mortality rates against autopsy findings have concluded, contradictorily, both that the numbers are unacceptable [4 288/id] and that the overall numbers are largely reliable [5 239/id]. During the last two decades, as diagnostic technology and procedures have continued to improve, only a limited number of studies have been published validating mortality statistics on stroke or ischemic heart disease against autopsy findings [6 304/id, 7 276/id, 8 282/id]. These studies were based on cohorts selected for postmortem examinations, and thus not able to address external validity. In Norway, the official department known as Statistics Norway compiles information on time and cause of death for all deceased inhabitants. The mortality statistics regarding stroke and ischemic heart disease in Norway have not been validated against autopsy findings since 1977 [5 239/id].

The aims of this study were to compare the accuracy of the diagnoses given in the mortality statistics between stroke and ischemic heart disease against autopsy findings, and to identify predictors of a general post mortem examination being carried out.

\section{Methods}

\section{Study population}

A random, population-based sample of 6,811 subjects aged 20-75 in 1964 was invited to the Bergen Clinical Blood Pressure Survey (1965-1971). Information from their medical history and from a standardized clinical examination was recorded for each of the participants. The study details have been extensively described elsewhere [9 266/id, 10 154/id]. Registration of mortality began on 1 January 1964 and ended on the date of death, date of emigration or on 31 December 2005, whichever occurred first.
Mortality statistics

Since 1964 all residents of Norway have been assigned a unique 11-digit identification number which includes their date of birth. Name, address and identification number are registered by the Central Population Register of Statistics Norway, which by law must be kept up-to-date regarding deaths and emigration. When a registered Norwegian dies inside Norwegian borders, a death certificate is issued by a physician, and sent to Statistics Norway. A death registered on the basis of a medical death certificate is matched with the corresponding identification number in the Central Population Register. The registered underlying cause of death is the disease (or injury) that initiates the series of events that eventually leads to death [11 305/id]. Notification of time, place and cause of death were obtained from Statistics Norway and linked to our data file on the basis of the identification numbers, with permission granted by the Data Inspectorate, the Norwegian Directorate of Health and Social Services, and the Regional Committee for Ethics in Medical Research. Statistics Norway used the 7th, 8th, 9th and 10th revision of the International Classification of Diseases (ICD) during the study period from 1964 to 2005 (Table 1). The causes of death were grouped into the 65 causes in the "European shortlist" (Eurocodes) which are used in the European official mortality statistics [12 307/ id]. The analyses were based on mortality from ischemic heart disease (Eurocode 34, ICD10 I20-I25) and cerebrovascular disease (Eurocode 36, ICD10 I60-69), having been given as the underlying cause of death.

\section{Autopsy records}

The autopsy assessments of the causes of death in this cohort have previously been published [13 290/id].

Necropsy findings were recorded by means of SNOMED codes. The Norwegian SNOMED has been prepared by the Norwegian Pathology Association Code and Nomenclature Committee in cooperation with the Competence Center for IT in the health and social sector, and is based on the Systematized Nomenclature of Medicine [14 291/id]. The selection of SNOMED codes which identifies autopsy-verified fatal

Table 1 ICD codes (and corresponding ICD versions) used in Norway during the study period covered by the variables fatal stroke and coronary death [22 292/id]

\begin{tabular}{clll}
\hline Year of death & $\begin{array}{l}\text { ICD-version } \\
\text { in use }\end{array}$ & $\begin{array}{l}\text { Fatal stroke } \\
\text { (Eurocode 36) }\end{array}$ & $\begin{array}{l}\text { Coronary death } \\
\text { (Eurocode 34) }\end{array}$ \\
\hline $1964-1968$ & $6 / 7$ & $330-334$ & 420,422 \\
$1969-1985 /$ & $8 / 9$ & $430-438$ & $410-414$ \\
$1986-1995$ & & I60-I69 & I20-I25 \\
$1996-2005$ & 10 & &
\end{tabular}


strokes and coronary deaths is given in Table 5 in the "Appendix".

\section{Statistical analyses}

The causes of death recorded in the mortality statistics and at autopsy from the Gade Institute Department of Pathology were compared and tabulated according to the following categories:

True positive: a correct match with the diagnosis from the mortality statistics and at autopsy.

Over-diagnosed (false positive): case diagnosed in the mortality statistics but not at autopsy. Over-diagnosed (\%) is the proportion of false positives divided by all the positives according to the mortality statistics (test).

Under-diagnosed (false negative): case diagnosed at autopsy but not in the mortality statistics. Under-diagnosed $(\%)$ is the proportion of false negative cases divided by all the positives according to the autopsy records (truth).

Sensitivity of the diagnosis in mortality statistics was calculated as the proportion of true positives divided by all the positives according to autopsy records.

Positive predictive value (PPV) was calculated as the number of true positives divided by all the positives according to the mortality statistics.

Overall agreement between the mortality statistics and the autopsy results was assessed by Cohen's kappa and its 95\% confidence interval [15 297/id]. Kappa can be interpreted as the proportion of agreement beyond chance, and Cohen's kappa is the most commonly used kappa-type statistic in epidemiological studies [16 296/id]. We adopted the Landis and Koch classification [17 295/id], classifying kappa between 0.00 and 0.20 as poor agreement; $0.21-0.40$ fair agreement; $0.41-0.60$ moderate agreement; $0.61-0.80$ substantial agreement, and 0.81-1.00 almost perfect agreement. Cox proportional hazard regression was used to test the influence of hypertension upon stroke mortality or death from ischemic heart disease defined by mortality statistics (Eurocode 36 or 34) and autopsy records, respectively, in order to assess whether the results were comparable. Binary logistic regression was used to explore potential predictors of autopsy. Analyses were performed using SPSS software, version 15.0.

\section{Results}

\section{Study population}

By the end of 41 years of the study, 4,387 persons ( $64 \%$ of the cohort) had died and 1,140 of these (26\%) were examined by autopsy at the Gade Institute. The ratio of autopsies to the number of deaths decreased from $40 \%$ in the period $1964-1975$ to $11 \%$ in the period $1995-2005$. The autopsy ratio for the upper quartile of age at death (i.e. 84-103 years) fell from 25 to $4 \%$. In participants dying from stroke (according to mortality statistics), the autopsy ratio decreased from 41 to $4 \%$, whereas in those dying from coronary heart disease it decreased from 38 to $14 \%$.

Of the 1,140 subjects examined by autopsy at the Gade Institute in Bergen only 742 (65\%) of the autopsy-reports were forwarded and/or recorded in the mortality statistics (Fig. 1).

Of the specific causes of death recorded in mortality statistics, 3,389 (77\%) were not based on autopsy findings. The 256 cases of death recorded at Statistics Norway as having been examined by autopsy, but with no autopsy record at the Gade Institute, were evenly distributed over the entire period of the study ("Appendix" Fig. 2). Until 1996 Statistics Norway recorded that the registered cause of death was based on an autopsy if the physician issuing the Death Certificate had indicated that an autopsy had been planned, but in many of these instances a post mortem examination never took place. The 398 individuals with autopsy records available at the Gade Institute, but with cause of death "not based on autopsy" in the mortality statistics died mainly in the period before 1987 when physicians ordering the post mortem examination were still responsible for forwarding the results of the autopsy to Statistics Norway. From 1987 the pathology departments were responsible for forwarding the autopsy reports and from 1996 Statistics Norway implemented systematic procedures to adjust the registered cause of death according to the findings of the autopsy ("Appendix" Fig. 3).

Validity of the diagnosis of fatal strokes in Norwegian mortality statistics

The validity of the diagnosis of fatal stroke in the mortality statistics was assessed by comparing the mortality statistics for which diagnosis had been based on autopsy results with those for which it had not (Table 2). The prevalence of fatal strokes in the mortality statistics was the same in the two groups $(34 / 398=8.5$ vs. $64 / 742=8.6 \%)$.

Ofthe28under-diagnosed(falsenegative)fatalstrokesinthe mortality statistics, theregisteredcauses of deathwerediseases of the circulatory system (Eurocode 33 ) in 12 cases (including ischemic heart disease (Eurocode 34) in 9 cases), pneumonia (Eurocode39)in5cases,malignantneoplasm(Eurocode07)in4 cases and otherEurocodesin 7 cases.

Of the 13 over-diagnosed (false positive) fatal strokes reported in the mortality statistics, the autopsy had identified diseases of the circulatory system in 9 cases (including ischemic heart disease in 5 cases), diseases of the lungs/ airways in 2 cases, malignant neoplasm in 1 case and 1 other case. 
Fig. 1 Mortality and autopsy data for the 6,811 survey participants

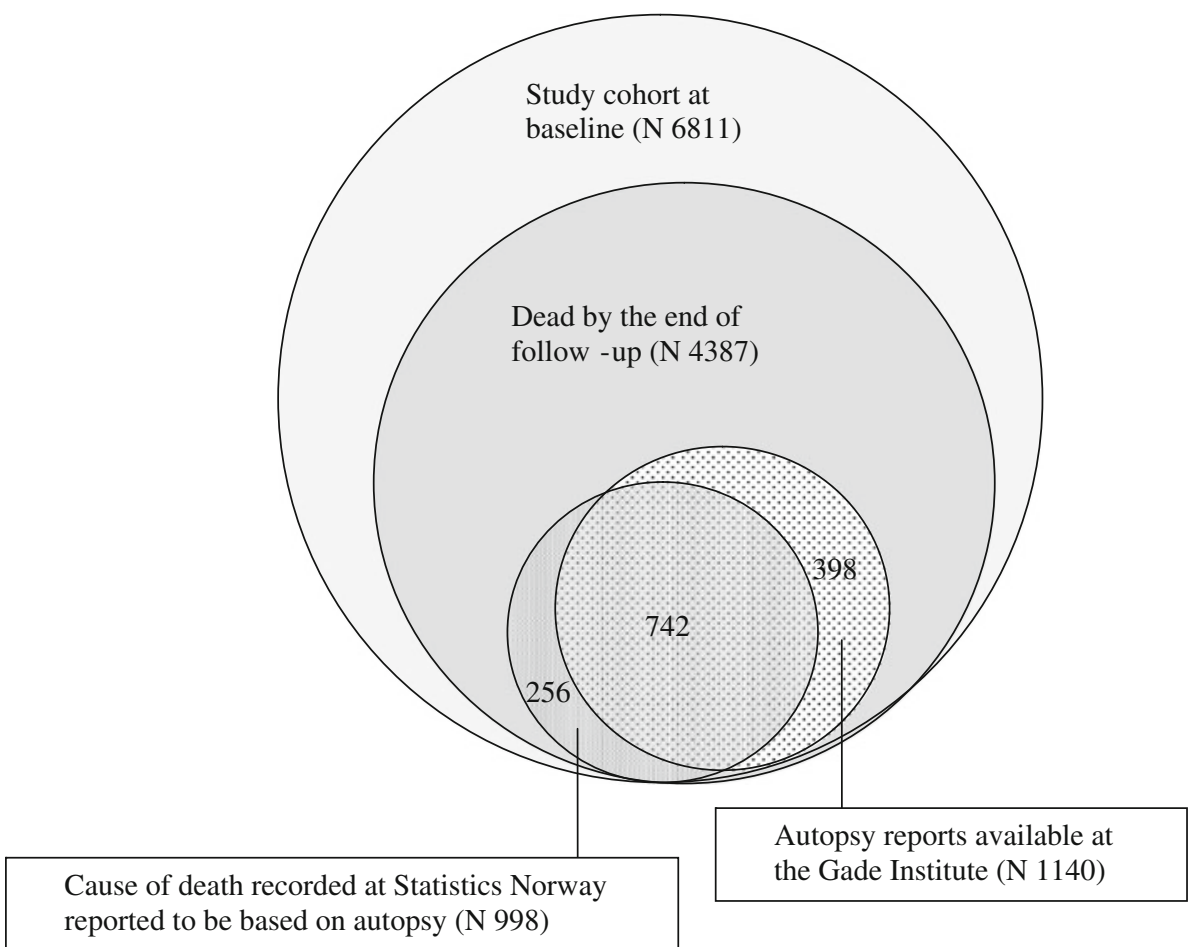

Table 2 Validity of fatal strokes (Eurocode 36) recorded in Norwegian mortality statistics for 1,140 post mortem examinations, according to whether the autopsy results were available or not

\begin{tabular}{llllll}
\hline Eurocode 36 & $\begin{array}{l}\text { Sensitivity } \\
{[95 \% \mathrm{CI}]}\end{array}$ & $\begin{array}{l}\text { Positive predictive value } \\
{[95 \% \mathrm{CI}]}\end{array}$ & $\begin{array}{l}\text { Over-diagnosed } \\
{[95 \% \mathrm{CI}]}\end{array}$ & $\begin{array}{l}\text { Under-diagnosed } \\
{[95 \% \mathrm{CI}]}\end{array}$ & $\begin{array}{l}\text { Kappa } \\
{[95 \% \mathrm{CI}]}\end{array}$ \\
\hline Autopsy reported available & $60 / 83=0.72$ & $60 / 64=0.94$ & $4 / 64=0.06$ & $23 / 83=0.28$ & 0.80 \\
& {$[0.63,0.82]$} & {$[0.88,1.00]$} & {$[0.003,0.12]$} & {$[0.18,0.37]$} & {$[0.72,0.87]$} \\
Autopsy reported unavailable & $25 / 30=0.83$ & $25 / 34=0.74$ & $9 / 34=0.29$ & $5 / 30=0.17$ & 0.76 \\
& {$[0.70,0.97]$} & {$[0.59,0.88]$} & {$[0.12,0.41]$} & {$[0.03,0.30]$} & {$[0.64,0.88]$} \\
Total & $85 / 113=0.75$ & $85 / 98=0.87$ & $13 / 98=0.14$ & $28 / 113=0.25$ & 0.79 \\
& {$[0.67,0.83]$} & {$[0.80,0.93]$} & {$[0.07,0.20]$} & {$[0.17,0.33]$} & {$[0.73,0.85]$} \\
\hline
\end{tabular}

CI confidence interval

For fatal strokes the kappa coefficient indicated "substantial" agreement irrespective of whether autopsy results were available to inform the mortality statistics or not (Table 2). The positive predictive value of fatal stroke in mortality statistics was slightly improved when autopsy results were available, but the change of sensitivity was not statistically significant (based on the overlapping of confidence intervals).

The kappa coefficients calculated for the 4 different quartiles of the follow-up period (before 1978, 1978-1986, 1987-1995, 1996-2005) were 0.83, 0.77, 0.70, and 0.85 respectively, showing no trend of increasing diagnostic validity over time.

As hypertension is the most established risk factor for cerebral stroke, we tested whether hypertension had predicted fatal stroke according to the mortality statistics differently from fatal stroke according to the autopsy records. We used Cox proportional hazard regression, adjusted for age at the baseline examination (when the blood pressure was measured) and for gender. With fatal stroke from mortality statistics as the outcome the hazard ratio was $1.71,95 \% \mathrm{CI}[1.4,2.08]$ and as the outcome from autopsy records the hazard ratio was $1.70,95 \%$ CI $[1.07$, 2.68].

Validity of the diagnosis of coronary deaths in Norwegian mortality statistics

As for stroke, the recorded coronary deaths in the mortality statistics were divided into subgroups according to whether the diagnoses were based on autopsy results or not, and the validity of the mortality statistics was assessed (Table 3 ). 
Table 3 Validity of coronary deaths (Eurocode 34) recorded in Norwegian mortality statistics for 1,140 post mortem examinations, according to whether the autopsy results were available or not

\begin{tabular}{|c|c|c|c|c|c|}
\hline Eurocode 34 & $\begin{array}{l}\text { Sensitivity } \\
{[95 \% \mathrm{CI}]}\end{array}$ & $\begin{array}{l}\text { Positive predictive value } \\
{[95 \% \mathrm{CI}]}\end{array}$ & $\begin{array}{l}\text { Over-diagnosed } \\
{[95 \% \mathrm{CI}]}\end{array}$ & $\begin{array}{l}\text { Under-diagnosed } \\
{[95 \% \mathrm{CI}]}\end{array}$ & $\begin{array}{l}\text { Kappa } \\
{[95 \% \mathrm{CI}]}\end{array}$ \\
\hline Autopsy reported available & $\begin{array}{l}219 / 237=0.92 \\
{[0.89,0.96]}\end{array}$ & $\begin{array}{l}219 / 253=0.87 \\
{[0.82,0.91]}\end{array}$ & $\begin{array}{l}34 / 253=0.13 \\
{[0.09,0.18]}\end{array}$ & $\begin{array}{l}18 / 237=0.08 \\
{[0.04,0.11]}\end{array}$ & $\begin{array}{l}0.84 \\
{[0.79,0.88]}\end{array}$ \\
\hline Autopsy reported unavailable & $\begin{array}{l}65 / 87=0.75 \\
{[0.66,0.84]}\end{array}$ & $\begin{array}{l}65 / 79=0.82 \\
{[0.74,0.91]}\end{array}$ & $\begin{array}{l}14 / 79=0.17 \\
{[0.09,0.26]}\end{array}$ & $\begin{array}{l}23 / 87=0.25 \\
{[0.17,0.36]}\end{array}$ & $\begin{array}{l}0.73 \\
{[0.64,0.81]}\end{array}$ \\
\hline Total & $\begin{array}{l}284 / 324=0.88 \\
{[0.84,0.91]}\end{array}$ & $\begin{array}{l}284 / 332=0.86 \\
{[0.82,0.89]}\end{array}$ & $\begin{array}{l}48 / 332=0.15 \\
{[0.11,0.18]}\end{array}$ & $\begin{array}{l}40 / 324=0.12 \\
{[0.09,0.16]}\end{array}$ & $\begin{array}{l}0.80 \\
{[0.76,0.84]}\end{array}$ \\
\hline
\end{tabular}

CI confidence interval

The prevalence of coronary deaths in the mortality statistics was 79/399 (20\%) in the subgroup where autopsy results had been reported as unavailable, whereas it was $253 / 742(34 \%)$ in the subgroup where autopsy results had been reported as available.

Of the 40 under-diagnosed (false negative) coronary deaths in the mortality statistics, the registered causes of death were diseases of the circulatory system (Eurocode 33 ) in 20 cases (of which stroke (Eurocode 36) in 5 cases), respiratory diseases (Eurocode 37) in 7 cases, malignant neoplasm (Eurocode 07) in 7 cases and others in 6 cases. Of the 48 over-diagnosed (false positive) coronary death reports in the mortality statistics, the autopsy reports concluded on diseases of the circulatory system in 20 cases (of which stroke in 9 cases), diseases of the lungs/airways in 11 cases and malignant neoplasm in 2 cases, and others in 15 cases.

For coronary deaths the kappa coefficient increased from "substantial" to "almost perfect" agreement when the autopsy results were available to the mortality statistics. The sensitivity of ischemic heart disease in the mortality statistics was slightly improved when the autopsy results were available, but for the positive predictive value the difference was not statistically significant (based on the overlapping confidence intervals).

In the 4 quartiles of the study period the combined kappa coefficients were $0.81,0.79,0.81$, and 0.83 , respectively.

With coronary death (Eurocode 34) from the mortality statistics as the outcome the Cox proportional hazard ratio associated with hypertension was $1.58,95 \%$ CI [1.38, 1.82]. With coronary death verified from the autopsy record as the outcome the hazard ratio was $1.5295 \%$ CI $[1.17,1.99]$, both adjusted for age at baseline and gender.

Predictors of post mortem examination and the association to fatal stroke

The selection of deaths for autopsy in a general population is not random. We tested the following potential predictors for effect upon the odds of undergoing post mortem examination: age at death (quartiles), period of death (before 1987 vs. 1987 or later), gender, and cause of death (cerebral stroke or coronary disease). The independent variables were explored in bivariate and multivariate analyses. Bivariate logistic regression included only the predictor of interest and the outcome (autopsy). Multivariate logistic regression included gender, age at death and period of death. Cause of death was compared to all other deaths (Table 4).

As can be seen from Table 4, death from cerebral stroke was a negative predictor of referral for autopsy, whereas death from coronary heart disease was not, both adjusted for gender, period of death and age at death. Female gender was also a negative predictor of autopsy. There was no statistically significant interaction between the categorical variables included in these analyses.

\section{Discussion}

Our study indicates that the validity of fatal cerebral stroke as well as that of coronary death in the Norwegian mortality statistics for the city of Bergen seems to be satisfactory. The kappa coefficients, sensitivity and positive predictive values range between 0.71 and 0.92 . Our findings are largely supported by the limited number of previous studies in this area [7 276/id, 3 285/id, 6 304/id]. Forty years ago a Norwegian study based on autopsy records [5 239/id] also concluded that the over-all figures for stroke deaths are generally reliable in the mortality statistics.

The kappa coefficient of both the diagnoses fatal stroke and ischemic heart disease in the mortality statistics did not change significantly during the study period or across the different ICD versions in use (results not shown). This is somewhat surprising, as we have experienced an increased access to more advanced diagnostic procedures over the last decades, improving the accuracy of both diagnoses in general. The fatal strokes may be clinically more obvious 
Table 4 Predictors of autopsy for 4,387 subjects who died during follow-up

\begin{tabular}{|c|c|c|c|c|}
\hline & \multicolumn{2}{|l|}{ Autopsy } & \multirow[t]{2}{*}{ OR bivariate $(95 \% \mathrm{CI})$} & \multirow[t]{2}{*}{ OR multivariate $(95 \% \mathrm{CI})$} \\
\hline & Yes $(n=1,140)$ & No $(\mathrm{n}=3,247)$ & & \\
\hline \multicolumn{5}{|l|}{ Gender } \\
\hline Male & $688(59)$ & $1,416(45)$ & 1 & 1 \\
\hline Female & $475(41)$ & $1,763(55)$ & $0.57(0.50,0.66)$ & $0.73(0.63,0.84)$ \\
\hline \multicolumn{5}{|l|}{ Age at death } \\
\hline$<68$ & $410(35)$ & $651(20)$ & 1 & 1 \\
\hline $68-75$ & $366(32)$ & $690(21)$ & $0.84(0.71,1.01)$ & $0.91(0.76,1.09)$ \\
\hline $76-83$ & $258(22)$ & $900(28)$ & $0.46(0.38,0.55)$ & $0.56(0.46,0.68)$ \\
\hline $84+$ & $129(11)$ & $983(31)$ & $0.21(0.17,0.26)$ & $0.32(0.25,0.41)$ \\
\hline \multicolumn{5}{|l|}{ Year of death } \\
\hline 1964-1986 & $747(64)$ & $1,316(41)$ & 1 & 1 \\
\hline 1987-2005 & $416(36)$ & $1,908(59)$ & $0.38(0.33,0.44)$ & $0.55(0.47,0.63)$ \\
\hline Fatal stroke & $100(9)$ & 448 (14) & $0.58(0.46,0.72)$ & $0.66(0.52,0.84)$ \\
\hline Coronary death & $336(29)$ & 785 (24) & $1.25(1.07,1.45)$ & $1.09(0.93,1.27)$ \\
\hline
\end{tabular}

OR Odds ratio, $C I$ confidence interval, $n$ number of cases

than the non-fatal strokes and the diagnostic accuracy of these cases may thereby be less influenced by the increasing access to advanced technology. While the disagreement between autopsy results and clinical diagnoses remains fairly stable [18 303/id], the number of post mortem examinations decreases. This may well result in an increase in diagnostic errors in the future.

We found limited differences in the accuracy of the mortality statistics according to whether the diagnoses were autopsy-based or not. The value of an autopsy is only adequately exploited if the results are correctly incorporated into mortality statistics. In previous studies up to $40 \%$ of autopsied cases were not properly reported in mortality statistics [19 300/id, 20 301/id]. The results from 421 $(36 \%)$ autopsies conducted at the Gade Institute were not taken into account by Statistics Norway (Fig. 1). These autopsy results, which were mostly from the period before 1987, may not have been forwarded by the physician ordering the post mortem examination. Some of the 256 cases without autopsy records at the Gade Institute, but which had been reported as having autopsy results in the mortality statistics, may have died and undergone autopsy outside the city of Bergen. The routines regarding reception and implementation of these data at Statistics Norway may thus be in need of improvement. The proportion of nonrecorded autopsy results has decreased during the study period but there might still be a potential for improvement.

Finally, we found that fatal stroke, increasing age and female gender are negative predictors of post mortem examination, whereas coronary deaths are not, which agrees with the findings of a Finnish study [8 282/id]. It has previously been shown that the location where death takes place also contributes to the demand for autopsy (hospital deaths are examined much more often than nursing home deaths and death in surgical wards more often than deaths in medical wards). Furthermore, more uncertain clinical diagnoses tend to be selected for autopsy and the pathologists tend to favor the more unusual diagnostic groups [13 290/id, 21 302/id]. Lack of interest in autopsy may also reflect lack of clinical involvement or therapeutic frustration. Thus the selection for post mortem examination is not random.

Limitations to this study are the limited sample size and that the necropsy findings are collected from a closed cohort, whereas the official mortality statistics record information on deaths in the entire (open) population. Thus incidence rates may not be comparable across the autopsy group and mortality statistics in general. Participation in the Bergen Clinical Blood Pressure Survey was not a predictor of selection towards autopsy (results not shown), so our findings are roughly applicable to an age-matched selection of subjects recorded in mortality statistics between 1965-2005. We found under-representation of the elderly, of females and of fatal strokes among the autopsyinvestigated deaths. This means that younger males, who were not assumed to be dead from stroke (atypical strokes?) tended to be examined post mortem. This skewness would rather deflate than exaggerate the correlation between mortality statistics and autopsy findings. The false positive and false negative rates in this cohort ranged from 5 to $29 \%$. Approximately half of the mismatches remained inside the circulatory system, whereas the others were more or less randomly distributed over the entire spectrum of diseases, which reduces the risk of systematic errors. 
Epidemiological research using endpoints defined as fatal stroke or ischemic heart disease from mortality statistics is unlikely to be markedly biased and that the validity regarding the fatal strokes is acceptable for this age-range. Our findings may also be applicable to international mortality statistics based on similar sources of data.

\section{Conclusion}

We have shown substantial validity of fatal cerebral strokes and coronary deaths in Norwegian mortality statistics, though there is still some potential for improvement.

Acknowledgments We wish to thank Anne Gro Pedersen and Finn Gjertsen for valuable information regarding the history of Norwegian mortality statistics and Andreas Henriksen for statistical support. The University of Oslo supported the research reported in this paper. The Norwegian Council for Cardiovascular Disease, the World Health Organization and the Research Foundation for Thoracic Medicine, University of Bergen, Norway, gave financial support for the Clinical Survey in Bergen in 1964-1971, data management and quality controls of the files.

Conflict of interest None of the authors has any proprietary interest in the results nor is there any financial conflict of interest.

Open Access This article is distributed under the terms of the Creative Commons Attribution Noncommercial License which permits any noncommercial use, distribution, and reproduction in any medium, provided the original author(s) and source are credited.

\section{Appendix}

See Table 5; Figs. 2, 3.

Table 5 Topographical and morphological SNOMED codes representing the underlying (alternatively immediate) cause of death from autopsy records regarding fatal strokes and coronary deaths

\begin{tabular}{lc}
\hline Localisation & T-code \\
\hline $\begin{array}{l}\text { Heart including } \\
\text { pericardium }\end{array}$ & $\begin{array}{c}31000,32000,32600,32910,33010,33030, \\
\text { Brain }\end{array}$ \\
\hline Morphological finding & M-code \\
\hline Infarct & $54700,38000,39000,39900,43000,43100$ \\
& $52110,52200,35100,35101,35190$, \\
& 35300,36050 \\
Haemorrhage & $37000,37001,37003,37004,38000,32000$, X2070, X7000 \\
& (also 58000, 32400, 324401, 32431, \\
& 32470,32471 (if T-code represents brain)) \\
& $32400,324401,32431,32470,32471$
\end{tabular}

SNOMED Systematic Nomenclature of Medicine (pathology-coding system), $T$-code topographical code, $M$-code, morphological code

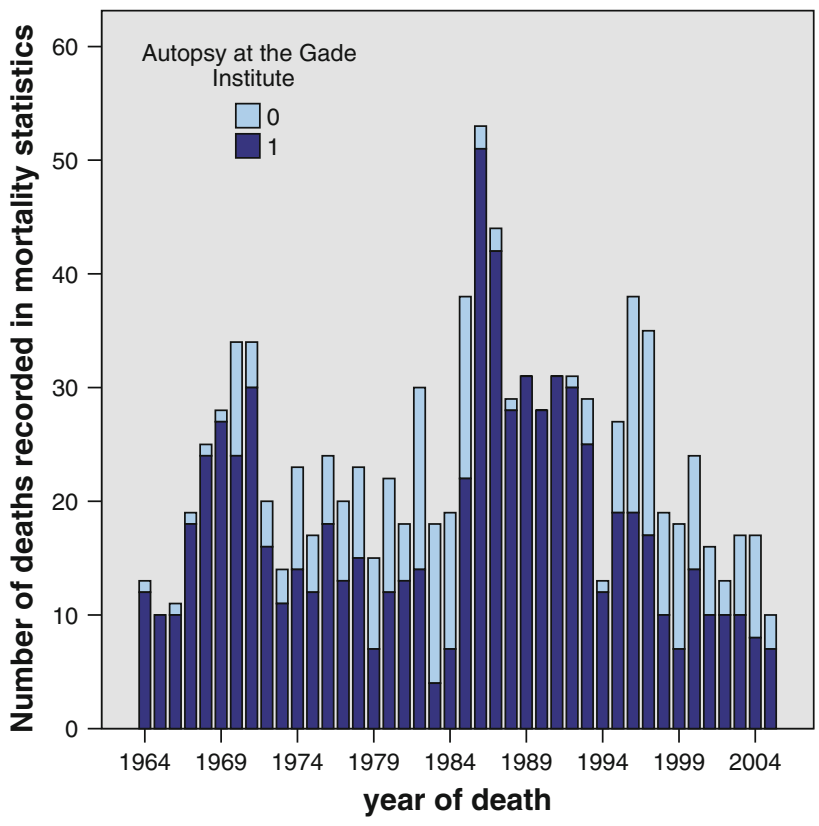

Fig. 2 Autopsy-based causes of death recorded in mortality statistics and the respective availability of autopsy data at the Gade Institute. ["light grey" $(\mathrm{N}=256$ cases $)$ denotes autopsies recorded in the mortality statistics, though autopsy data were not registered at Gade.]

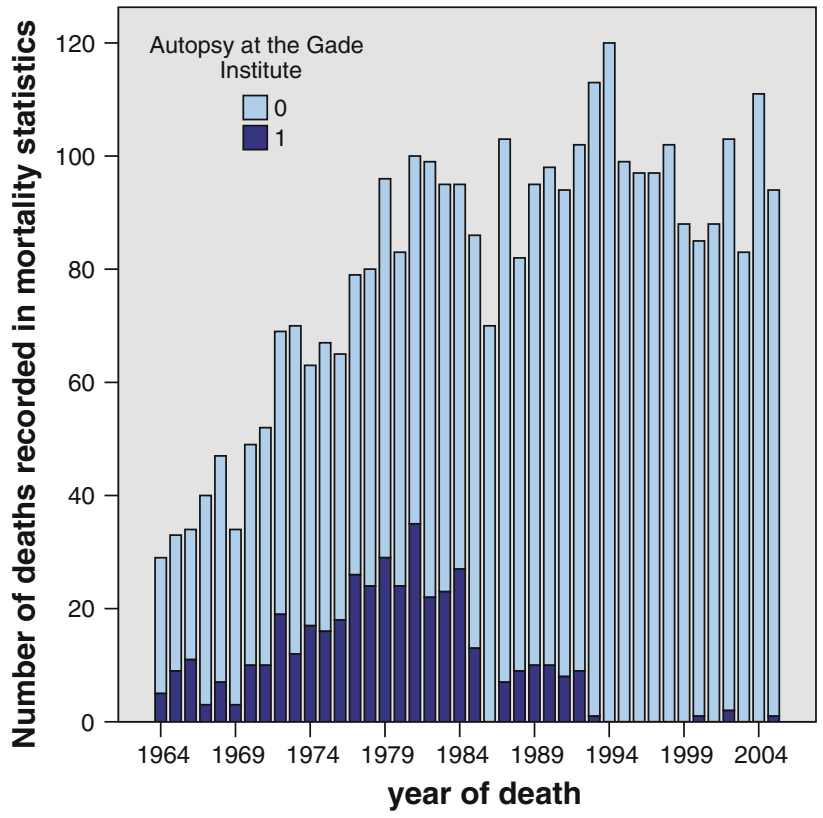

Fig. 3 Causes of death recorded without autopsy in mortality statistics and the respective availability of autopsy data at the Gade Institute. ["dark grey" ( $\mathrm{N}=398$ cases $)$ denotes autopsies at the Gade Institute, which were not registered in the mortality statistics.] 


\section{References}

1. World Health Organization. Mortality country fact sheet. Internet (2006) Available from: http://www.who.int/whosis/mort/profiles/ mort.euro.nor.norway.pdf.

2. Roulson J, Benbow EW, Hasleton PS. Discrepancies between clinical and autopsy diagnosis and the value of post mortem histology; a meta-analysis and review. Histopathology. 2005;47: 551-9.

3. Ravakhah KMMF. Death certificates are not reliable: revivification of the autopsy. South Med J. 2006;99:728-33.

4. Stehbens WE. Validity of cerebrovascular mortality rates. Angiology. 1991;42:261-7.

5. Torvik A, Stenwig JT. Changes in frequency of cerebrovascular diseases in Oslo, Norway, 1958-1977. An autopsy study. Stroke. 1981;12:816-23.

6. Saad R, Yamada AT, Pereira da Rosa FH, et al. Comparison between clinical and autopsy diagnoses in a cardiology hospital. Heart. 2007;93:1414-9.

7. Sington JD, Cottrell BJ. Analysis of the sensitivity of death certificates in 440 hospital deaths: a comparison with necropsy findings. J Clin Pathol. 2002;55:499-502.

8. Lahti RA, Sarna S, Penttil A. Exploitation of autopsy in determining natural cause of death: trends in Finland with special reference to the diagnostics of ischemic heart diseases and cerebrovascular diseases in middle-aged males, 1974-1993. Forensic Sci Int. 1998;91:109-21.

9. Gulsvik AK, Thelle DS, Mowe M, et al. Increased mortality in the slim elderly. A 42 year follow-up study in a general population. Eur J Epidemiol. 2009;24:683-90.

10. Gulsvik A, Humerfelt S, Bakke PS, et al. Norwegian population surveys on respiratory health in adults: objectives, design, methods, quality control and response rates. Clin Respir J. 2008;2: $10-25$.
11. World Health Organization. Cause of death definition. 2010. Available from: http://www.who.int/healthinfo/statistics/mortdata/ en/index.html.

12. Eurostat. European shortlist for causes of death. 2010. Available from: http://ec.europa.eu/eurostat/ramon/nomenclatures/index. cfm?TargetUrl=LST_NOM_DTL\&StrNom=COD_1998.

13. Hartveit F. Clinical and post-mortem assessment of the cause of death. J Pathol. 1977;123:193-210.

14. Competence Center for IT in the health and social sector AS. The Norwegian SNOMED. 2010. Available from: http://www.kith. no/templates/kith_WebPage 1192.aspx.

15. Cohen J. A coefficient of agreement for Nominal scales. Educ Psychol Meas. 1960;20:37-46.

16. Thompson WD, Walter SD. A reappraisal of the kappa coefficient. J Clin Epidemiol. 1988;41:949-58.

17. Landis JR, Koch GG. The measurement of observer agreement for categorical data. Biometrics. 1977;33:159-74.

18. Grade MH, Zucoloto S, Kajiwara JK, et al. Trends of accuracy of clinical diagnoses of the basic cause of death in a university hospital. J Clin Pathol. 2004;57:369-73.

19. Florey CD, Senter MG, Acheson RM. A study of the validity of the diagnosis of stroke in mortality data. I. Certificate analysis. Yale J Biol Med. 1967;40:148-63.

20. Engel LW, Strauchen JA, Chiazze L Jr, et al. Accuracy of death certification in an autopsied population with specific attention to malignant neoplasms and vascular diseases. Am J Epidemiol. 1980;111:99-112.

21. Karwinski B, Hartveit F. Death certification: increased clinical confidence in diagnosis and lack of interest in confirmation by necropsy is not justified. J Clin Pathol. 1989;42:13-7.

22. Folkehelseinstituttet. Codebook Cause of Death Register 1951-2004. 2010. Available from: http://www.fhi.no. 